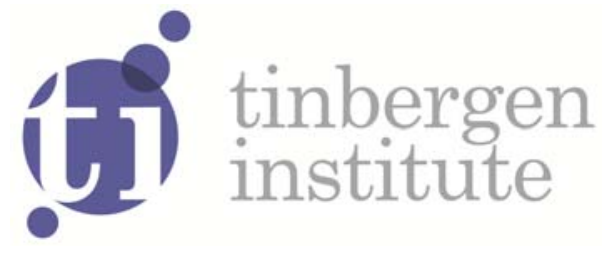

\title{
Do Floods have Permanent Effects? Evidence from The Netherlands
}

Trond G. Husby

Henri L.F. de Groot*

Marjan W. Hofkes

Martijn I. Dröes

* Tinbergen Institute. 
Tinbergen Institute is the graduate school and research institute in economics of Erasmus University Rotterdam, the University of Amsterdam and VU University Amsterdam.

More TI discussion papers can be downloaded at http://www.tinbergen.nl

Tinbergen Institute has two locations:

Tinbergen Institute Amsterdam

Gustav Mahlerplein 117

1082 MS Amsterdam

The Netherlands

Tel.: +31(0)205251600

Tinbergen Institute Rotterdam

Burg. Oudlaan 50

3062 PA Rotterdam

The Netherlands

Tel.: +31(0)10 4088900

Fax: $+31(0) 104089031$

Duisenberg school of finance is a collaboration of the Dutch financial sector and universities, with the ambition to support innovative research and offer top quality academic education in core areas of finance.

DSF research papers can be downloaded at: http://www.dsf.nl/

Duisenberg school of finance

Gustav Mahlerplein 117

1082 MS Amsterdam

The Netherlands

Tel.: +31(0)20 5258579 


\title{
DO FLOODS HAVE PERMANENT EFFECTS? EVIDENCE FROM THE NETHERLANDS*
}

\author{
Trond G. Husby \\ VU University Amsterdam, Institute for Environmental Studies (IVM), \\ De Boelelaan 1087, 1081 HV Amsterdam, the Netherlands. E-mail: trond.husby@vu.nl.
}

\section{Henri L.F. de Groot}

VU University Amsterdam, Department of Spatial Economics, Tinbergen Instituut and Ecorys NEI, De Boelelaan 1105, 1081 HV Amsterdam, the Netherlands.

E-mail: h.l.f.de.groot@vu.nl.

\section{Marjan W. Hofkes}

VU University Amsterdam, Faculty of Economics and Business Administration, and Institute for Environmental Studies (IVM), De Boelelaan 1105, 1081 HV Amsterdam.E-mail: m.w.hofkes@vu.nl.

\section{Martijn I. Dröes}

VU University Amsterdam, Department of Spatial Economics, and University of Amsterdam, Faculty of Economics and Business, De Boelelaan 1105, 1081 HV Amsterdam.E-mail: m.droes@vu.nl.

\begin{abstract}
This study investigates the short- and long-run impact on population dynamics of the major flood in the Netherlands in 1953. A dynamic difference-in-differences analysis reveals that the flood had an immediate negative impact on population growth, but limited long term effects. In contrast, the resulting flood protection programme (Deltaworks), had a persisting positive effect on population growth. As a result, there has been an increase in population in flood prone areas.
\end{abstract}

${ }^{*}$ We are grateful to two anonymous reviewers and the editor of this journal for very useful and constructive comments. Financial support from Kennis Voor Klimaat is gratefully acknowledged. At the time the article was written Martijn Dröes was employed at TNO, Built Environment and Geosciences. The usual disclaimer applies. 


\section{INTRODUCTION}

Hurricane Katrina, but also more recently Hurricane Sandy, remind us about the potentially severe consequences of natural disasters. These hurricanes made large stretches of land uninhabitable, destroyed local communities, and left many unemployed. Although estimates vary, some have suggested that the economic cost of Hurricane Katrina alone may well be as large as 150 billion US dollars (Neumayer, Plümper, and Barthel, 2013).

Even though the death toll of natural disasters has decreased over the past decades due to early-warning systems, stricter building codes, but also better evacuation routines, the economic costs of disasters have increased as population has at the same time concentrated in disaster-prone areas (IPCC, 2012). Moreover, although large scale natural disasters are rather unique events, especially in developed countries, if a disaster does occur it directly creates a demand for policy intervention to mitigate the impact of the disaster, including any potential future disasters, possibly further increasing the clustering of population in risky areas (Boustan, Kahn, and Rhode, 2012; Kahn, 2005). This raises the question to what extent governmental disaster protection is actually partially counteracted by individual responses as revealed by household location decisions.

To examine how natural disasters, and the ensuing government policies, affect population dynamics is difficult because the full effect of such disasters and related policies may take decades to unfold. To find evidence of such effects, we have to dig deep into history. In 1953, a substantial part of the Netherlands was flooded due to a combination of strong winds and a high tide. As a result, the Dutch government started a disaster prevention program (the Deltaworks) which resembles programs that are being proposed today for other locations at or below sea level, such as New York City.

The aim of this paper is to investigate the impact of the Great North Sea Flood of 1953 and the construction of the Deltaworks on population dynamics in the Netherlands. We utilize data on population levels for all municipalities in the Netherlands between 1947 and 2000. We use a dynamic difference-in-differences approach to estimate the effect of the flood and Deltaworks on the growth of population. The Deltaworks consist of five separate projects which were constructed and finalised at different points in time and space. It is this variation in treatment that we exploit to identify the dynamic response of population to the flood and the Deltaworks.

The results in this paper show that municipalities that were affected by the flood had population growth levels one year after the flood that were about 0.6 percentage points lower than in non-affected municipalities. These negative effects, however, did not persist over time. In the long run, the municipalities that were hit by the flood had, as a result of the Deltaworks, an annual growth rate of about 0.75 percentage points higher than the growth rate in non-affected municipalities. This relatively small difference in annual growth rates may lead to considerable differences in population levels over a longer period of time. Since our results suggest that population concentrates in areas that can potentially become inundated, serious challenges to flood risk management may arise regarding both the optimal degree of flood protection as well as risk financing

Our results are based on unique long time series data with a relatively large level of regional detail. This provides us with an opportunity to study population dynamics following a unique and highly interesting sequence of events. As such, this paper contributes to an expanding literature studying the dynamics of the spatial distribution of people and economic activity after an important historical event (e.g. the theory of increasing returns and the theory of locational fundamentals, a discussion we will briefly touch upon). Whereas much of the existing literature focuses on man-made disasters (e.g. Davis and Weinstein, 2002, 2008; Gerritsen, 2005), we study a natural disaster that was followed by man-made interventions. 
The remainder of this paper is organized as follows. Section 2 contains a concise literature review. Section 3 discusses the historical background of the 1953 flood and the Deltaworks flood protection program. The data and methodology are presented in Sections 4 and 5. Section 6 shows the results, while Section 7 provides the conclusions.

\section{DISASTERS AND POPULATION DYNAMICS}

A growing literature has attempted to estimate the economic impact of disasters. This research spans various macroeconomic modelling approaches (Rose and Guha, 2004; Rose and Liao, 2005; Hallegatte and Ghil, 2008; Okuyama, 2008) as well as empirical studies on different regional levels (Noy, 2009; Kousky, 2012). Despite a wide variety of approaches and definitions adopted in these studies, expected losses attributable to disasters are ultimately driven by the likelihood of the disaster (the hazard) and the consequences should it take place (the exposure). Recent research identifies the latter as the most important factor (Kahn, 2005; Pielke Jr, Gratz, Landsea, Collins, Saunders, and Musulin, 2008; Bouwer, 2011). The growth of population in coastal areas and areas subject to river floods are a particular source of concern in relation to expected sea level rise (IPCC, 2012).

A general finding in the empirical literature on disasters is that economic effects tend to disappear after a few years, at least in developed countries (Noy, 2009). Xiao (2011), for example, found that per capita income in flooded counties in the U.S. rebounded to pre-flood conditions, if not higher, in the years after the flood. One possible explanation is that the occurrence of a disaster provides an impetus for governmental action aimed at reducing hazard. Boustan et al. (2012) argue that government disaster relief programmes may partly have cancelled out individual responses, leading people to return or move to hazard-prone areas. Furthermore, flood mitigation measures in the form of large infrastructure projects may have a transformative role on local economies. Hornbeck and Naidu (2012) argue that an exodus of black workers led to an increased mechanisation of flooded counties in the South of the U.S. Given that a reduction of flood risk frequently involves substantial sunk costs or implementation of essentially irreversible policy measures, predictions on long-term effects of both disasters and risk reduction measures following in their wake could provide valuable inputs to policy makers. Such an exercise does, however, entail discussing why people choose to settle in some areas and not in others.

The spatial distribution of population over time as well as its underlying dynamics, have been widely discussed in the literature on man-made disasters (Davis and Weinstein, 2002, 2008; Bosker, Brakman, Garretsen, and Schramm, 2008; Redding, 2010). Theoretical explanations include random growth (Gabaix, 1999), locational fundamentals (Krugman, 1996), and increasing returns (Henderson, 1974). Random growth theory explains the distribution of people as a result of a random distribution of growth rates across space. The locational fundamentals theory posits that the economic attractiveness of each location is determined by some fundamental geographical factors, that are also randomly distributed. The theory of increasing returns explains the size of cities as a result of agglomeration forces inherent in modern economies. According to the theory of locational fundamentals, we should not expect to find any long-term effects from the flood in 1953, seeing that the flood left the distribution of these fundamentals unaltered. A finding of long-term effects would, however, be in line with the theory of increasing returns. If the flood had transformative effects on local labour- or housing markets, the result could be a new equilibrium population size in affected areas. 


\section{HISTORICAL BACKGROUND}

\section{Floods and policy: the Dutch case}

The mere topography of the Netherlands explains the central role of flood protection in Dutch policy making. As Figure 1 indicates, one quarter of the land is situated below mean sea level and the country hosts the estuary of four large rivers. In case of a storm surge at sea or high river discharges, as much as two thirds of the country would be inundated. Not surprisingly, Dutch history and institutions are marked by the constant fight against water. The Dutch Water Boards, dating back to the twelfth and thirteenth century, were given the responsibility for flood safety in their particular regions. Following their establishment, a systematic enclosing of rivers and formation of polders began. Current flood defences are to some extent an extension of protection strategies outlined centuries ago. The main protection against river flooding continues to be dikes, whereas dunes offer the most important defence against sea-water intrusion.

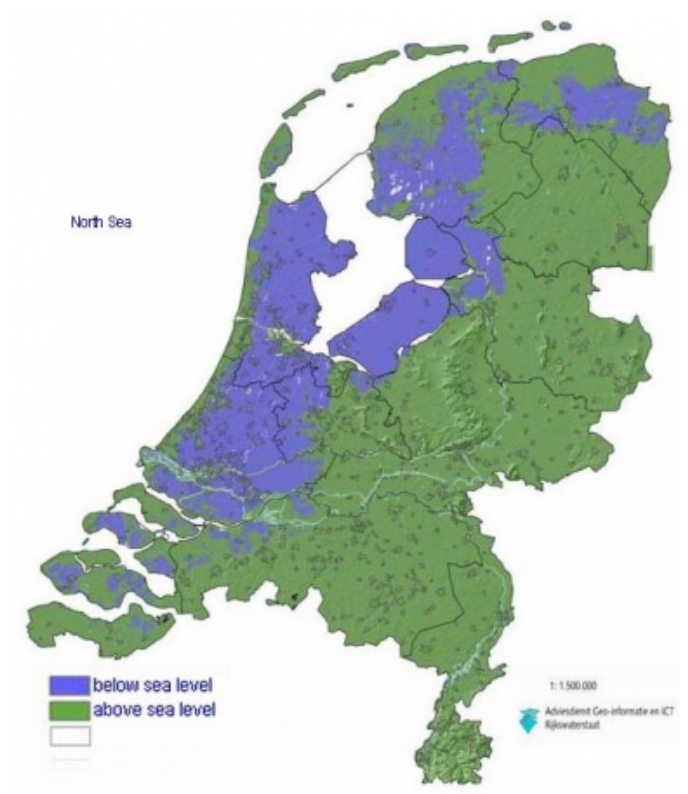

FIGURE 1: The Netherlands, above and below sea-level. Source: Rijkswaterstaat (2013).

The country has nevertheless been hit by several major flood disasters over the centuries. Some of them have played a large role in shaping flood management policies. The flood of 1916 is one clear example of the influence of floods on the policy process. Although not among the deadliest or the costliest in economic terms, the flood provided an important impulse for the creation of the Afsluitdijk which protected the north western part of the country by closing off the South Sea (Zuiderzee). The construction of the Afsluitdijk also exemplifies another important feature of Dutch flood policies: motives other than flood protection are often important in the political decision making. Closing off of the Zuiderzee led to the creation of a large freshwater lake (IJsselmeer) and enabled the creation of an entirely new province, viz. Flevoland. This secured fresh water supply and made large areas of new land available. Studies conducted before the second World War had already concluded that the flood protection in the south eastern 
part of the Netherlands would offer inadequate protection under certain extreme weather conditions. However, the second World War and the reconstruction in its aftermath, had pushed concerns for flooding down on the political agenda (Deltawerken, 2013).

\section{The flood}

Saturday January 31. 1953 at 6.00 P.M., an emergency telegram was sent out from the Royal Netherlands Meteorological Institute (KNMI), reporting strong north western winds and unusually high water in the North Sea. Due to poor early-warning routines, the message was hardly noticed by the population in the south western parts of the Netherlands. In the early morning when the peak of the tide occurred, a large part of the population was sleeping. The combination of high water and storm resulted in simultaneous dike breaches across the south-western provinces (see Figure 2).

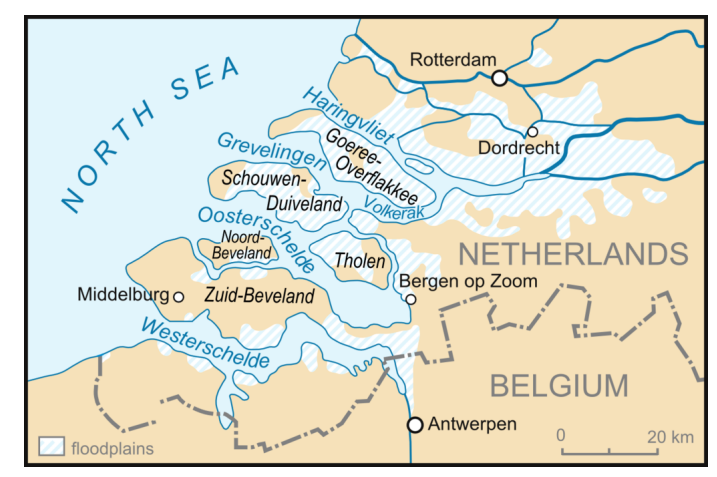

FIGURE 2: Inundated areas as a result of the flood. Source: Wikipedia.

Poor building quality as well as inadequate evacuation routines probably resulted in an excessive number of casualties (Van der Klis, Baan, and Asselman, 2005). The disaster could, however, have had far graver consequences. The dikes on the northern side of the Hollandse IJssel which protected the populous and economically important Randstad region, were in poor condition and only through some desperate and unorthodox action a major catastrophe was avoided (such actions included jamming a ship in a dike to plug gaping holes thereby preventing water from flowing through). A major flood in the Randstad - region would most certainly have led to a more than tenfold increase in the number of casualties and almost unimaginable economic damage (Deltawerken, 2013). Still, the devastations resulted in a total of 1836 casualties and in the destruction of 4,500 houses. Some 140,000 hectares of land remained flooded for a longer period, leading to the evacuation of approximately 100,000 people (De Kraker, 2006).

\section{The policy response}

As was the case with the flood in 1916 and the construction of the Afsluitdijk, the flood in 1953 provided an immediate impulse for action. Some strengthening of dikes had already been implemented by 1950, but the 1953-flood set the stage for the establishment of the Deltacommission which in effect had the task of determining Dutch flood management for several decades. The response took the form of the Deltaworks plan which aimed at closing certain river mouths and sea arms as well as strengthening existing and building new dikes (see Figure 3 for the measures taken in regions hit by the 1953 flood). 


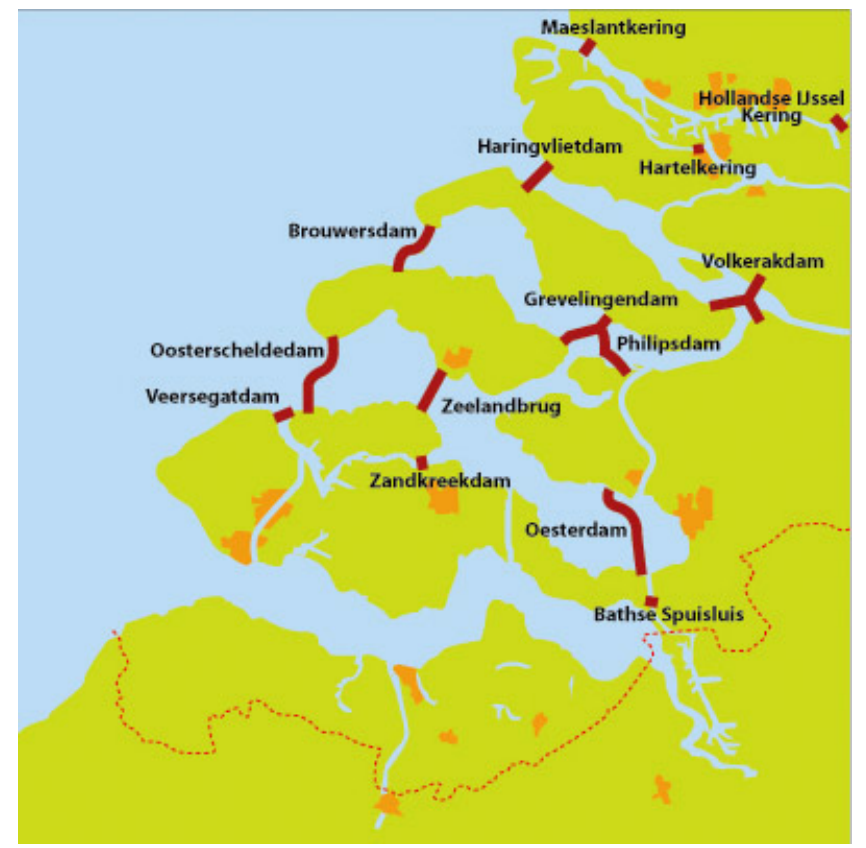

FIGURE 3: The Deltaworks. Source: Deltawerken (2013).

The first project of the Deltaworks was the storm barrier at the Hollandse IJssel, completed in 1958. This was a direct response to the devastations resulting from the 1953-flood. The project included strengthening existing dikes as well as the construction of a storm surge barrier, consisting of huge steel screens which could be lowered into the water in case of exceptionally high water levels. The next phase of the Deltaworks Plan was The Three Islands Plan which included the construction of Veersegatdam and Zandkreekdam, both finished in 1961. These were built to improve safety in areas affected by the flood. The Grevelingendam (1965) and Volkerakdam (1969) were secondary dams, meaning that their primary function was to facilitate the construction of other dams. Grevelingendam and Volkerak were built to facilitate the construction of two of the most complex constructions of the Deltaworks Programme: the Haringvlietdam and the Brouwersdam, both completed in 1971 (Deltawerken, 2013; Pilarczyk, 2007).

\section{DATA}

We use annual population data at municipality-level covering the period 1947-2000. Data were retrieved from two sources: the Historical Database of Dutch Municipalities (HDNG) - a data base consisting of municipal level statistics from the Dutch censuses starting in 1795 until present (Beekink, Boonstra, Engelen, and Knippenberg, 2003) and from Statistics Netherlands (CBS). The former covers the time period from 1947 to 1959 , while the latter covers 1960 to 2000 . The data set was limited to this period as this covers a reasonable before/after period for the 1953-flood and the construction of the Deltaworks. It was decided to make an upper cut-off at 2000, as it was assumed that any additional years would not greatly improve the quality of the analysis.

The use of such long time series obviously poses some challenges as the number of municipalities has changed substantially over the years. The number of municipalities 
in 2000 is not even half of that a 100 years earlier (Beekink et al., 2003, p. 158). In order to create a consistent data set it was therefore necessary to account for changes in the borders of municipalities. This was achieved through the creation of a concordance table, using the municipalities as they were defined in 2000 and then tracing them back in time. From 1960 this proved to be a relatively straightforward, although tedious, procedure, as both numbers of inhabitants as well as the area transferred between municipalities are listed by CBS. Before 1960 the information about municipal changes comes from Van der Meer and Boonstra (2006) which only includes information about border changes but not about the number of people 'transferred' between municipalities. We refer to Appendix A for a more detailed discussion of the data set.

\section{METHODOLOGY}

\section{Difference-in-differences with response functions}

The data described were organised as a panel with population size for $m=1, \ldots, 531$ municipalities in years $t=1947, \ldots, 2000$. Population growth is defined as the difference in the natural logarithm. As Figure A1 in Appendix A suggests, heterogeneity across both time and space is present in the data.

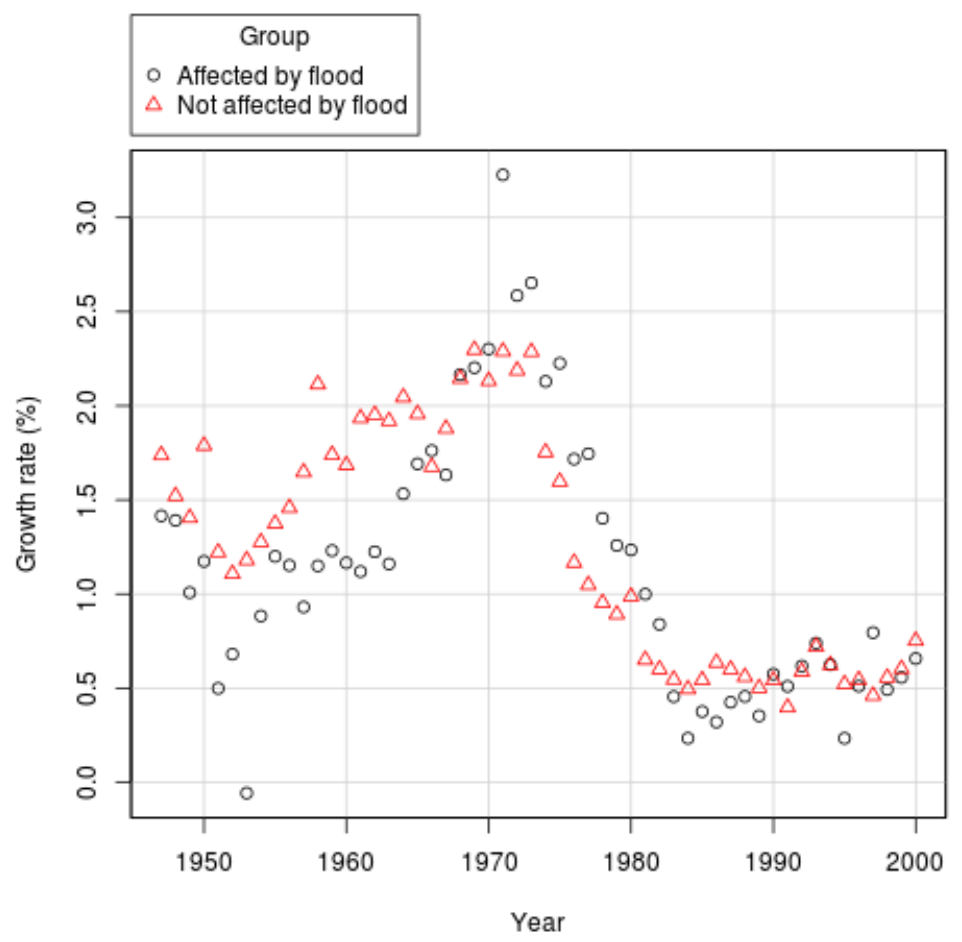

FIGURE 4: Mean population growth in control and treatment group (flood).

The central topic of this paper is to investigate whether post-disaster trends in population growth rates diverge between municipalities which were (treatment group) and were not (control group) affected by the flood in 1953. An important prerequisite 
for such an analysis is that the treatment and control group follow similar trends before the disaster. Figure 4 plots growth rates in treatment and control groups over time. The figure does already suggest that there is a common, downward trend in population growth in both groups in the period right after 1947. Then there is change in the direction of the trend in both groups. In Figure 5, the treatment group consists of municipalities which were affected by the Deltaworks programme while the control group consists of non-affected municipalities. This figure is very similar to Figure 4.

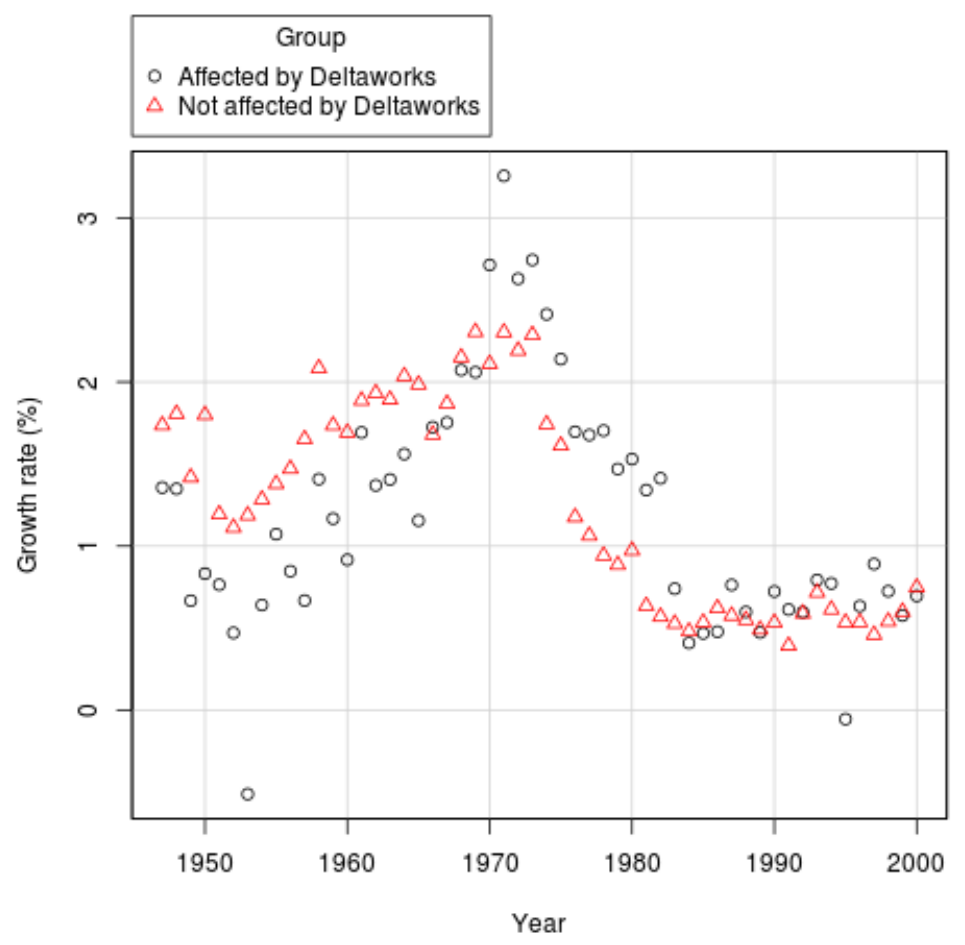

FIGURE 5: Mean population growth in control and treatment group (Deltaworks).

One major challenge with difference-in-differences analyses is to isolate the effect of the treatment from other possibly confounding factors. In our case with a data set covering an almost 60-year period this poses a serious problem. A shift in land use resulting from a shrinking importance of the agricultural sector is one candidate source. Falling fertility rates in the southern provinces of the Netherlands may also cause a bias. We control for these potential biases in our empirical model by including fixed effects as well as municipality-specific trend-variables. Since our main interest is to investigate whether the effects on population growth rates are temporary or permanent, we decide to follow the approach in Wolfers (2006) who uses a response function consisting of yearly dummy variables instead of the commonly employed before-after dummy variable. This allows us to investigate the dynamic response of population growth explicitly. 


\section{Estimated models}

The pure flood model is used to investigate the dynamic effects from the flood in 1953. It is specified as follows:

$$
\begin{aligned}
g_{m, t} & =\alpha+\sum_{k \geq 0} \beta_{k} \text { Flood }_{m, k, t}^{R F}+\left[\sum_{m} \text { Municipality }_{m} * \text { Trend }_{t}\right] \\
& +\sum_{t} T F E_{t}+\sum_{m} M F E_{m}
\end{aligned}
$$

The dependent variable (population growth) is calculated using the natural logarithm: $g_{m, t} \equiv \ln \left(\mathrm{Pop}_{m, t} / \mathrm{Pop}_{m, t-1}\right) . T F E_{t}$ and $M F E_{m}$ are time- and municipality-fixed effects, respectively. We estimate two models, one with a municipality-specific trend variable and one without. We also tried alternative specifications of the model which included quadratic trends as well as the inverse of the linear trend, without major changes to our results. The response function is represented by $\sum_{k>0} \beta_{k} F l o o d_{m, k, t}^{R F}$, where $k$ represents the number of years since the flood or since the completion of a protective measure, taking the value 1 in the treatment-group in period $k$ and zero otherwise. For the response function in Equation (1), $k=0$ corresponds to $t=1953$ for all municipalities which were affected by the flood. We define $k=0,1, \ldots, 15, o 15$ where $o 15$ covers all time-periods beyond 15 years after the flood. This means that the dummy variable $F l o o d_{m, o 15, t}^{R F}$ takes the value one after 1968 and zero otherwise. Population was counted on December 31, so that the dependent variable actually measures the percentage population growth in $t$. The interpretation of the coefficient $\beta_{k}$ is the percentage point difference in the population growth rate between the treatment and the control group at $k$ years after the flood.

In the second model, the Deltaworks (DW) model, the response function from Equation (1) is replaced with a similar function for the Deltaworks:

$$
\begin{aligned}
g_{m, t} & =\alpha+\sum_{k \geq 0} \eta_{k} D W_{m, k, t}^{R F}+\left[\sum_{m} \text { Municipality }_{m} * \text { Trend }_{t}\right] \\
& +\sum_{t} T F E_{t}+\sum_{m} M F E_{m}
\end{aligned}
$$

One major difference between the response function from Equation (1) and that of Equation (2) is that the 'treatment' year (i.e. the year corresponding to $k=0$ ) differs between the municipalities in the treatment group in the latter case. This is due to the fact that various parts of the Deltaworks were finished in different years. This allows us to better isolate the effects from the Deltaworks.

Finally, we estimate a model controlling for both the effect of the flood and the Deltaworks simultaneously:

$$
\begin{aligned}
g_{m, t} & =\alpha+\gamma D W_{m, t}^{B A}+\sum_{k \geq 0} \beta_{k} \text { Flood }_{m, k, t}^{R F} \\
& +\left[\sum_{m} \text { Municipality }_{m} * \text { Trend }_{t}\right]+\sum_{t} T F E_{t}+\sum_{m} M F E_{m}
\end{aligned}
$$

$D W_{m, t}^{B A}$ in the mixed model in Equation (3) represents a simple before-after treatment for a flood, and is a dummy-variable that takes the value one in affected municipalities (treatment group) in all time periods after the completion of a relevant construcion of the Deltaworks and zero otherwise. The basic idea behind this model is that the Deltaworks may itself represent an omitted variable in the model in Equation (1). 


\section{Coding of treatment variables}

In the case of the 1953 flood it is relatively straightforward to categorise municipalities. It is well-documented which municipalities were affected, both in terms of deaths and material damage (Van der Klis et al., 2005; Deltawerken, 2013). For the Deltaworks Programme the definition is more complicated. It is clear that a dike breach around Rotterdam would have affected large parts of the Randstad area, and not only the areas close to the water. In the face of the difficulties related to defining the spatial extent of the protection, the choice has been to define treatment municipalities as only those directly affected by the mitigation efforts. For example, the treatment group in the first period of the construction of the Deltaworks are municipalities that border the Hollandse IJssel. The affected municipalities in each treatment group are plotted in Figures B1 and B2 in Appendix B.

\section{RESULTS}

\section{The Flood Model}

The estimates of the parameters of the flood model in Equation (1) are presented in the left part of Table 1. An F-test confirmed that the dummy variables forming the response function were jointly statistically significant. The inclusion of the trend variable does only marginally alter the estimates, and, interestingly, the effect seems to be growing over time. Prior to the flood the true trend of population growth is, if anything, slightly negative, and the inclusion of a linear trend variable should therefore not change the estimates much. However, from the late 1950s to around 1970 the true trend in population growth is increasing, suggesting that the trend variable captures the true trend.

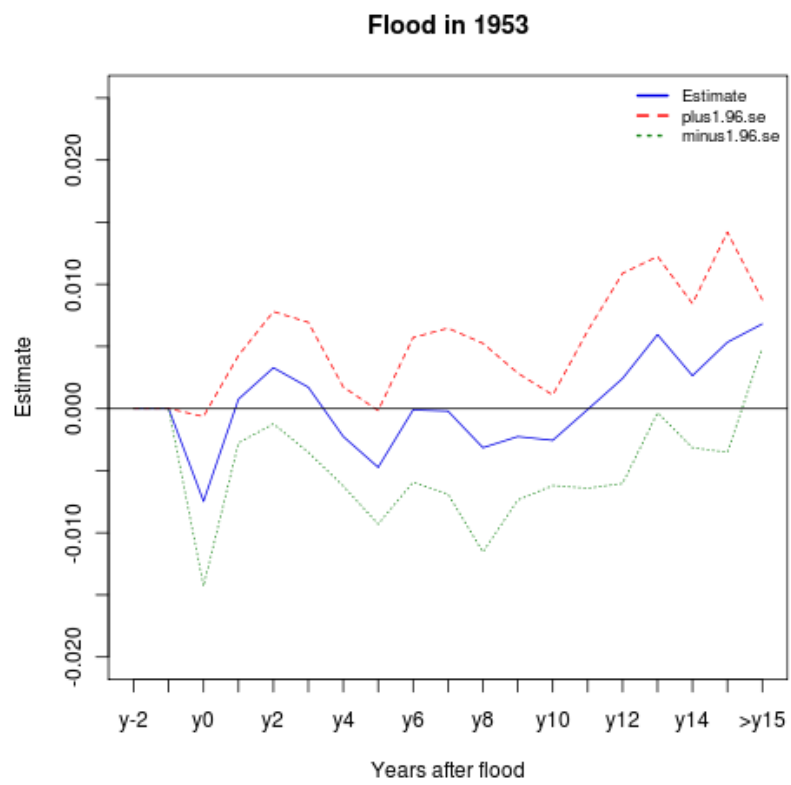

FIGURE 6: The response function of the flood model

Based on the previous discussion, one would expect an event such as the flood in 1953 
to have had a dramatic effect on the population in affected areas: crops were affected for years by the intrusion of sea water, providing a striking blow to the agricultural sector. At the same time the destruction of large parts of the housing stock meant that people in many cases had no houses to return to. Such effects were also suggested by Figure 4 , in which there appeared to be a reduction of growth rates in the early 1950s. The estimated response function in Equation (1), depicted in Figure 6 suggests that the flood had an immediate negative impact. It appears that affected municipalities suffered an immediate drop in population growth of about $0.6 \%$-points as compared to non-affected municipalities. Thereafter, the results are less clear cut. There is some weak evidence of a bounce-back effect the year following the flood, but this is statistically insignificant. In the following years the response function is mostly negative and statistically insignificant.

The estimated parameter values for the last dummy variable $\beta_{o 15}^{R F}$, however, is positive and statistically significant. This suggests that the growth rate in municipalities which were hit by the flood was, in each year, $0.75 \%$-points higher than in those municipalities that were not hit. Judging by the observations from the literature, it is questionable whether this positive permanent effect is directly related to the flood. As we shall see, it is likely that other factors than the flood are at least equally important in explaining the positive divergence from the trend.

\section{The Deltaworks Model}

The estimates of the parameters of the Deltaworks (DW) model of Equation (2) are presented in the right part of Table 1. Figure 7 depicts the estimated response function from Equation (2).

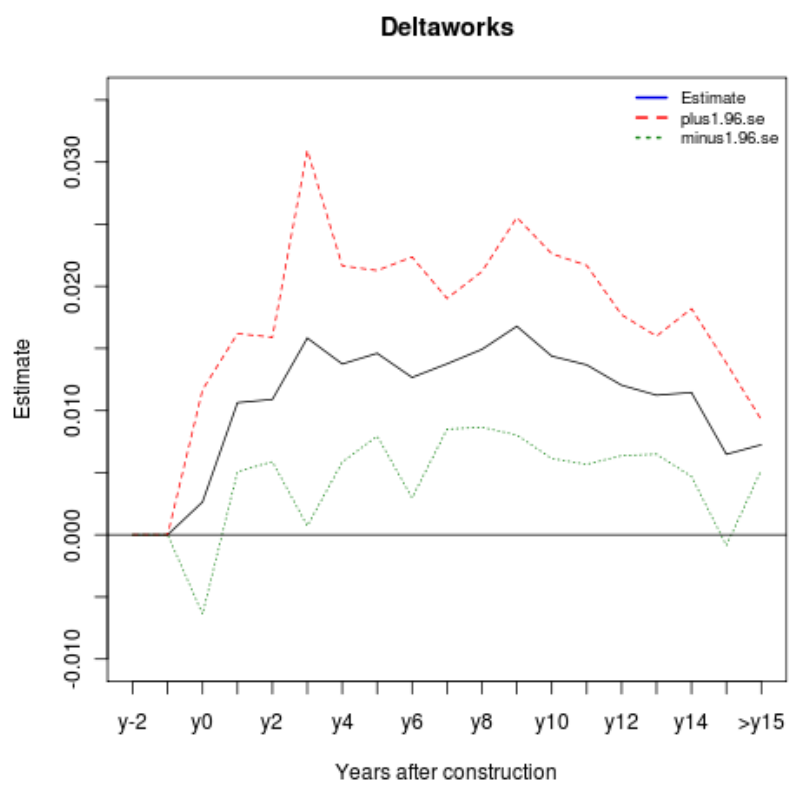

FIGURE 7: The response function of the DW Model.

As Figure 7 suggests, the Deltaworks programme had a positive effect overall. One initial factor may have been the construction phase itself, requiring manpower and 
supplies. The inflow of workers and increase in demand for goods may have caused positive ripple effects in local economies. Reconstruction of the housing stock and normalisation of the agricultural sector may also have played a part. However, as suggested by both Figure 5 and the regression coefficients in Figure 7, the largest difference between control and treatment group seems to occur from 1970 onwards. In other words, the construction of the different parts of the Deltaworks may itself have had a positive effect. But the effect is large and positive into the early 1980s - ten years subsequent to the finalisation of the major parts of the Deltaworks programme. This suggests again that factors, other than the more immediate ones discussed above, may be at play. One possible explanation is that the lowering of risk led households to move back or households living elsewhere to settle in affected areas. Another possible explanation is that the lowering of risk was accompanied by changes in land regulations: as more and more areas were offered better protection, more land was made available for development. The development led to construction of housing, which again may have caused positive ripple effects. Summing up, it seems likely that the positive effects found in the regression analysis for the 1953 flood stem from the construction of the Deltaworks.

\section{The Mixed Model}

A logical next step is to include the Deltaworks as a control in the regression for the 1953-flood. To this end, the Deltaworks dummy was included in the model with the response function for the flood (the mixed model, Table 1).

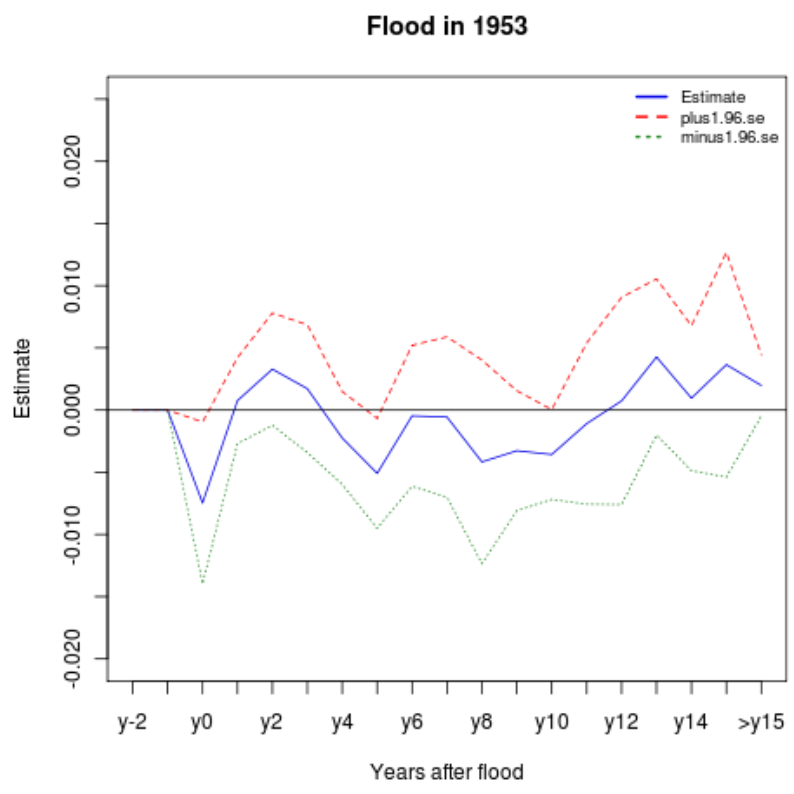

FIGURE 8: The response function of the mixed model.

Controlling for Deltaworks rendered the parameter value for the last dummy variable Flood $_{o 15}^{R F}$ statistically insignificant, and an F-test revealed that the dummy variables forming the response function were not jointly statistically significant. This does, again, suggest that the Deltaworks Programme is more important in explaining population 
growth than the 1953-flood. Figure 8 plots the response function, controlling for Deltaworks. Compared with Figure 6, we see that the last part of the dashed line is shifted downwards, meaning that positive effects from period 5 onwards are dampened: in this specification, no positive effects remain which are statistically significant at a 5\%-level, although the negative effects remain unchanged. The first parts of the Deltaworks were finalised 5 years after the flood (1958). Given the positive effects from the Deltaworks construction identified above, these results are not all that surprising. Summing up, we can conclude that the flood in 1953 slowed down the population growth in affected municipalities. There is some weak evidence suggesting that population growth stayed lower in non-affected areas for roughly ten years after the disaster. In the long run population growth in flood-affected municipalities stays above that of non-affected municipalities. Although some municipalities in the treatment group of the flood are coded as not directly affected by the Deltaworks, they may have been indirectly affected by the construction. This could explain the robust positive effects in the 1980s. As suggested above, any positive effects on population growth are most likely to be related to the Deltaworks rather than to the flood itself. 
TABLE 1: Regression results

\begin{tabular}{|c|c|c|c|c|c|c|}
\hline & Flood $\mathrm{n}$ & nodel & DW m & odel & Mixed $n$ & model \\
\hline (Intercept) & $0.0150^{* * *}$ & $0.0138^{* * *}$ & $0.0151^{* * *}$ & $0.0139^{* * *}$ & $0.0151^{* * *}$ & $0.0139^{* *}$ \\
\hline & $(0.0022)$ & $(0.0022)$ & $(0.0022)$ & $(0.0022)$ & $(0.0022)$ & $(0.0022)$ \\
\hline Before-after & & & & & $0.0084^{* * *}$ & $0.0086^{* *}$ \\
\hline & & & & & $(0.0012)$ & $(0.0012)$ \\
\hline Trend & & $-0.0000^{* * *}$ & & $-0.0000^{* * *}$ & & $-0.0000^{* *}$ \\
\hline & & $(0.0000)$ & & $(0.0000)$ & & $(0.0000)$ \\
\hline $\begin{array}{l}\text { Period after } \\
\text { the event }(k)\end{array}$ & & & & & & \\
\hline Year 0 & $-0.0075^{*}$ & $-0.0075^{*}$ & 0.0028 & 0.0026 & $-0.0075^{*}$ & $-0.0075^{*}$ \\
\hline & $(0.0035)$ & $(0.0035)$ & $(0.0046)$ & $(0.0046)$ & $(0.0033)$ & $(0.0033)$ \\
\hline Year 1 & 0.0007 & 0.0008 & $0.0103^{* * *}$ & $0.0106^{* * *}$ & 0.0007 & 0.0008 \\
\hline & $(0.0018)$ & $(0.0018)$ & (0.0028) & $(0.0028)$ & $(0.0018)$ & $(0.0018)$ \\
\hline Year 2 & 0.0032 & 0.0033 & $0.0106^{* * *}$ & $0.0109^{* * *}$ & 0.0032 & 0.0033 \\
\hline & $(0.0023)$ & $(0.0023)$ & $(0.0025)$ & $(0.0026)$ & $(0.0023)$ & $(0.0023)$ \\
\hline Year 3 & 0.0016 & 0.0017 & $0.0155^{*}$ & $0.0158^{*}$ & 0.0016 & 0.0017 \\
\hline & $(0.0027)$ & $(0.0027)$ & $(0.0077)$ & $(0.0077)$ & $(0.0026)$ & $(0.0026)$ \\
\hline Year 4 & -0.0024 & -0.0023 & $0.0134^{* * *}$ & $0.0137^{* * *}$ & -0.0024 & -0.0022 \\
\hline & $(0.0020)$ & $(0.0020)$ & $(0.0040)$ & $(0.0040)$ & $(0.0019)$ & $(0.0019)$ \\
\hline Year 5 & $-0.0049^{*}$ & $-0.0047^{*}$ & $0.0142^{* * *}$ & $0.0146^{* * *}$ & $-0.0052^{*}$ & $-0.0051^{*}$ \\
\hline & $(0.0023)$ & $(0.0023)$ & $(0.0034)$ & $(0.0034)$ & $(0.0023)$ & $(0.0023)$ \\
\hline Year 6 & -0.0003 & -0.0001 & $0.0122^{*}$ & $0.0127^{*}$ & -0.0006 & -0.0005 \\
\hline & $(0.0030)$ & $(0.0030)$ & $(0.0049)$ & $(0.0049)$ & $(0.0029)$ & $(0.0029)$ \\
\hline Year 7 & -0.0004 & -0.0002 & $0.0133^{* * *}$ & $0.0138^{* * *}$ & -0.0008 & -0.0006 \\
\hline & $(0.0034)$ & $(0.0034)$ & $(0.0027)$ & $(0.0027)$ & $(0.0033)$ & $(0.0033)$ \\
\hline Year 8 & -0.0034 & -0.0032 & $0.0145^{* * *}$ & $0.0149^{* * *}$ & -0.0044 & -0.0042 \\
\hline & $(0.0043)$ & $(0.0043)$ & $(0.0032)$ & $(0.0032)$ & $(0.0042)$ & $(0.0042)$ \\
\hline Year 9 & -0.0025 & -0.0023 & $0.0163^{* * *}$ & $0.0168^{* * *}$ & -0.0035 & -0.0033 \\
\hline & $(0.0026)$ & $(0.0026)$ & $(0.0045)$ & $(0.0045)$ & $(0.0025)$ & $(0.0025)$ \\
\hline Year 10 & -0.0028 & -0.0026 & $0.0139^{* * *}$ & $0.0144^{* * *}$ & $-0.0038^{*}$ & $-0.0036^{\dagger}$ \\
\hline & $(0.0019)$ & $(0.0019)$ & $(0.0042)$ & $(0.0042)$ & $(0.0018)$ & $(0.0018)$ \\
\hline Year 11 & -0.0003 & -0.0001 & $0.0132^{* *}$ & $0.0137^{* * *}$ & -0.0013 & -0.0011 \\
\hline & $(0.0032)$ & $(0.0032)$ & $(0.0041)$ & $(0.0041)$ & $(0.0033)$ & $(0.0033)$ \\
\hline Year 12 & 0.0021 & 0.0024 & $0.0115^{* * *}$ & $0.0120^{* * *}$ & 0.0005 & 0.0007 \\
\hline & $(0.0043)$ & $(0.0043)$ & $(0.0029)$ & $(0.0029)$ & $(0.0042)$ & $(0.0043)$ \\
\hline Year 13 & $0.0057^{\dagger}$ & $0.0060^{\dagger}$ & $0.0107^{* * *}$ & $0.0112^{* * *}$ & 0.004 & 0.0043 \\
\hline & $(0.0032)$ & $(0.0032)$ & $(0.0024)$ & $(0.0024)$ & $(0.0032)$ & $(0.0032)$ \\
\hline Year 14 & 0.0023 & 0.0026 & $0.0109^{* *}$ & $0.0114^{* * *}$ & 0.0007 & 0.001 \\
\hline & $(0.0030)$ & $(0.0030)$ & $(0.0034)$ & $(0.0034)$ & $(0.0030)$ & $(0.0030)$ \\
\hline Year 15 & 0.005 & 0.0053 & 0.006 & $0.0065^{\dagger}$ & 0.0033 & 0.0036 \\
\hline & $(0.0045)$ & $(0.0045)$ & $(0.0037)$ & $(0.0037)$ & $(0.0046)$ & $(0.0046)$ \\
\hline Over 15 years & $0.0062^{* * *}$ & $0.0068^{* * *}$ & $0.0067^{* * *}$ & $0.0072^{* * *}$ & 0.0014 & 0.002 \\
\hline & $(0.0010)$ & $(0.0010)$ & $(0.0010)$ & $(0.0010)$ & $(0.0012)$ & $(0.0013)$ \\
\hline$N$ & 28673 & 28673 & 28673 & 28673 & 28673 & 28673 \\
\hline$R^{2}$ & 0.2298 & 0.2304 & 0.231 & 0.2316 & 0.2313 & 0.2319 \\
\hline $\operatorname{adj.} R^{2}$ & 0.2134 & 0.214 & 0.2145 & 0.2152 & 0.2148 & 0.2154 \\
\hline Resid. sd & 0.0187 & 0.0187 & 0.0187 & 0.0187 & 0.0187 & 0.0187 \\
\hline
\end{tabular}

Robust standard errors in parentheses

$\dagger$ significant at $p<10 \% ;{ }^{*} p<5 \% ;{ }^{* *} p<1 \%$; ${ }^{* * *} p<0.1 \%$ 


\section{Stock dynamics from the flood and the Deltaworks}

In terms of population levels, our results suggest that the permanent effects of the Deltaworks had a much larger impact than the temporary effects of the flood. Figure 9 illustrates this point. There are two hypothetical municipalities - one in the control group and one in the treatment group, which both have an initial population $\left(\mathrm{Pop}_{0}\right)$ equal to 20,000 in 1952 . Their size at $\tau$ equals:

$$
\begin{aligned}
& \operatorname{Pop}_{\tau}^{\text {Control group }}=\mathrm{Pop}_{0} * \prod_{\tau=1953}^{2000}\left(1+\overline{g_{\tau}}\right) \\
& \mathrm{Pop}_{\tau}^{\text {Treatment group }}=\mathrm{Pop}_{0} * \prod_{\tau=1953}^{2000}\left(1+\overline{g_{\tau}}+\beta_{k}\right)
\end{aligned}
$$

The municipality in the control group grows with the average national growth rate each year $\left(\overline{g_{\tau}}\right)$, while the municipality in the treatment group grows with the growth rate plus the estimated coefficients ( $\beta_{k}$ for the relevant year) from Equation (1). By using this model we assume that the positive very long-term effects which were found(beyond 15 years), are related to the construction of the Deltaworks rather than to the flood. Treatment does in this case thus refer to both the flood and the Deltaworks.

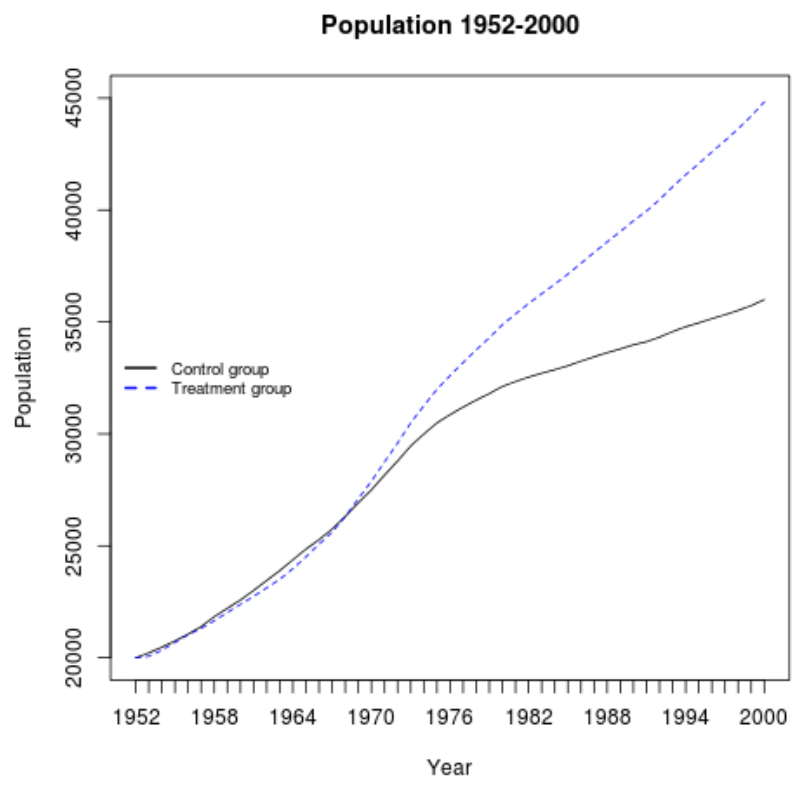

FIGURE 9: The stock effects predicted by the response function in the Flood model with time trend from Equation (1).

The results from this comparative exercise are depicted in Figure 9. Investigating the first 15 years, we see that the municipality in the treatment group suffers an immediate loss of population relative to the municipality of the control group. The population recovers quickly, and the difference is never larger than 400 inhabitants, meaning that the impacts from the flood on population levels were actually rather limited. When examining the the whole time period, we see that the (positive) very long term effects 
led to a substantial difference in population levels. The municipality in the control group has by the year 2000 nearly 9000 less inhabitants than the municipality in the treatment group. As such, the permanent effects resulting from the construction of the Deltaworks has a much larger effect on population levels than the temporary effects from the flood.

\section{CONCLUSION AND DISCUSSION}

Although the number of casualties resulting from disasters in developed countries tend to be limited, the monetary costs associated with them tend to be large. At the time of writing, preliminary estimates suggest that the flood which struck parts of Central Europe in June 2013 may have resulted in direct damages of approximately 10 billion Euros. A concentration of population and economic activities in hazardous areas is a main driver behind these losses. Thus, as countries grow richer and their ability to protect increases, disasters strike with less frequency, but result in greater monetary costs if they occur. People can respond to disasters by moving out of hazardous areas, but governments have strong incentives to react to a disaster by increasing protection, possibly crowding out individual responses. As such, studies investigating the long term impacts of disasters should analyse the disaster in conjunction with mitigation efforts following in its wake.

In this paper, we have examined the long-term impacts on population growth from the disastrous North Sea Flood in 1953 in the Netherlands. The flood provided an impetus to a large scale flood protection programme, the Deltaworks. Due to the unique characteristics of our data, we are able to analyse the effects from the flood while separating the influence of the Deltaworks. Our results suggest that the long-term effects on population growth were most likely not directly related to the flood in 1953 . The positive long term effects found were instead due to the policy interventions following the flood. Our analysis of the very long-term effects suggest that the population in municipalities which were affected by the flood had a yearly population growth of on average 0.6 $\%$-points higher than the municipalities which were not affected. Our hypothetical example illustrates the large effect on population levels due to the compounding nature of population growth. There is thus reason to believe that the Dutch government, through its Deltaworks Programme, was highly successful in crowding out individual responses to the disaster. This is an important policy lesson for other governments who see the Dutch experience as providing guidance for their own flood risk reduction programmes.

Our results are similar to those found in the literature on man-made disasters: temporary shocks such as a flood have limited long-term effects while policy interventions may well have such effects. Natural disasters differ from man-made disasters in the sense that the likelihood of them occurring is closely linked to geography. It is, for example, likely that the south west coast of the U.S. will be hit by hurricanes in the future. Consequently, the equilibrium population in hazardous areas should, at least partly, be determined by the likelihood that a disaster strikes. In light of the locational fundamentals theory, the limited long-term impacts from the flood are therefore not surprising since the flood did not alter the likelihood of future disasters. According to the theory of increasing returns a disaster may well have long-term effects. Several authors suggest that Katrina, through its destruction of cheap housing, in fact led to a new and lower equilibrium population of New Orleans (Glaeser, 2005; Vigdor, 2008). Our results therefore seem, at a first glance, to be at odds with the theory of increasing returns. But, in contrast to hurricane Katrina, the flood in 1953 led to a massive policy response. This policy response not only reduced flood risk - several of the constructions of the Deltaworks Programme had other purposes than flood protection - the constructions also provided freshwater supply as well as transport infrastructure. It is likely that local economies were fundamentally changed by these massive constructions. Subsequent to the construction of the protective measures, new land would be made available. In the 
Netherlands, a country with one of the highest population densities in the world, it is possible that new land available at lower prices led people to move to areas protected by the Deltaworks. In sum, the limited long term effects from the flood appear to be most in line with the theory of locational fundamentals while the positive long term effects from the Deltaworks seem more in line with the theory of increasing returns.

Throughout this paper we have interpreted our results such that reducing flood risk somehow leads people to settle in previously risky areas. As such, it is mainly a demandside story. But our analysis should be complemented with an analysis of the supply side. An investigation of house prices in the same time span would reveal whether the flood or the construction of the Deltaworks actually changed expectations. There is also reason to believe that the policy interventions affected the supply side of the land- and housing market. Therefore, an investigation of house prices could tell something about whether this is primarily a supply side or demand side story. ${ }^{1}$ Another interesting follow-up to this research would be an investigation of the interplay between the construction of the Deltaworks and changes in land use regulation. In sum, our narrative is not complete and there is plenty of room for further research. We hope therefore that our results will stimulate further research which can shed more light on the distribution of population and economic activities and the underlying mechanisms. Such research can provide valuable inputs in the process of preparing for the effects of future climate change.

\footnotetext{
${ }^{1}$ In the present study population dynamics are also interpreted as a crude proxy for economic growth. In a subsequent paper, Davis and Weinstein use industrial data to investigate multiple equilibria in population as well as in spatial distribution of size and composition of industries (Davis and Weinstein, 2008). Their results largely confirm the findings in Davis and Weinstein (2002), suggesting that the bombing had a similar effect on general economic indicators as on population.
} 


\section{REFERENCES}

Beekink, Erik, Onno Boonstra, Theo Engelen, and Hans Knippenberg. 2003. Nederland in Verandering. Maatschappelijke Ontwikkelingen in Kaart Gebracht 1800-2000. Aksant, Amsterdam.

Bosker, Maarten, Steven Brakman, Harry Garretsen, and Marc Schramm. 2008. "A Century of Shocks: The Evolution of the German City Size Distribution 1925-1999." Regional Science and Urban Economics 38(4), 330-347.

Boustan, Leah Platt, Matthew E. Kahn, and Paul W. Rhode. 2012. "Moving to Higher Ground: Migration Response to Natural Disasters in the Early Twentieth Century." American Economic Review 102(3), 238-44.

Bouwer, Laurens M. 2011. "Have Disaster Losses Increased due to Anthropogenic Climate Change?" Bulletin of the American Meteorological Society 0(92), 39-46.

Davis, Donald R. and David E. Weinstein. 2002. "Bones, Bombs, and Break Points: The Geography of Economic Activity." American Economic Review 92(5), 1269-1289.

- 2008. "A search for multiple equilibria in urban industrial structure." Journal of Regional Science 48(1), 29-65.

De Kraker, Adriaan M. J. 2006. "Flood Events in the Southwestern Netherlands and Coastal Belgium, 1400-1953." Hydrological Sciences Journal 51(5), 913-929.

Deltawerken. 2013. The official web-pages of the deltaworks programme. http: //www. deltawerken.com/.

Gabaix, Xavier. 1999. "Zipf's Law and the Growth of Cities." American Economic Review 89(2), $129-132$.

Gerritsen, Herman. 2005. "What Happened in 1953? The Big Flood in the Netherlands in Retrospect." Philos Transact A Math Phys Eng Sci 363.

Glaeser, Edward L. 2005. "Should the Government Rebuild New Orleans, or just Give Residents Checks?" The Economists' Voice 2(4).

Hallegatte, Stéphane and Michael Ghil. 2008. "Natural Disasters Impacting a Macroeconomic Model with Endogenous Dynamics." Ecological Economics 68(1-2), 582-592.

Henderson, J. Vernon. 1974. "The Sizes and Types of Cities." American Economic Review 64(4), $640-56$.

Hornbeck, Richard, and Suresh Naidu. 2012. "When the Levee Breaks: Black Migration and Economic Development in the American South." Working Paper 18296, National Bureau of Economic Research.

IPCC. 2012. Summary for Policymakers. In C. Field, V. Barros, T. Stocker, D. Qin, D. Dokken, K. Ebi, M. Mastrandrea, K. Mach, G.-K. Plattner, S. Allen, M. Tignor, and P. Midgley (Eds.) Managing the Risks of Extreme Events and Disasters to Advance Climate Change Adaptation. University Press, Cambridge, UK, and New York, NY, USA.

Kahn, Matthew E. 2005. "The Death Toll from Natural Disasters: The Role of Income, Geography, and Institutions." Review of Economics and Statistics 87(2), 271-284.

Kousky, Carolyn. 2012. "Informing Climate Adaptation: A Review of the Economic Costs of Natural Disasters, their Determinants, and Risk Reduction Options." Resources for the Future Discussion Paper (12-28).

Krugman, Paul. 1996. "Confronting the Mystery of Urban Hierarchy." Journal of the Japanese and International Economies 10(4), 399-418.

Neumayer, Eric, Thomas Plümper, and Fabian Barthel. 2013. "The Political Economy of Natural Disaster Damage." Global Environmental Change (0), Forthcoming.

Noy, Ilan. 2009. "The Macroeconomic Consequences of Disasters." Journal of Development Economics 88(2), 221-231.

Okuyama, Yasuhide. 2008. "Critical Review of methodologies on Disaster Impacts Estimation." Background paper for EDRR report.

Pielke Jr, Roger A., J. Gratz, C. W. Landsea, D. Collins, M. A. Saunders, and R. Musulin. 2008. "Normalized Hurricane Damage in the United States: 1900-2005." Natural Hazards Review 9(1), 29-42.

Pilarczyk, Krystian W. 2007. "Flood Protection and Management in the Netherlands." In O. Vasiliev, P. v. Gelder, E. Plate, and M. Bolgov (Eds.), Extreme Hydrological Events: New Concepts for Security. Springer.

Redding, Stephen J. 2010. "The Empirics Of New Economic Geography." Journal of Regional Science 50(1), 297-311.

Rijkswaterstaat. 2013. Dutch Ministry of Infrastructure and the Environment. http: //www.rijkswaterstaat.nl/.

Rose, Adam, and Gauri-Shankar Guha. 2004 "Computable General Equilibrium Modeling of Electric Utility Lifeline Losses from Earthquakes." Modeling Spatial and Economic Impacts of Disasters, 119-141.

Rose, Adam, and Shu-Yi Liao. 2005. "Modeling Regional Economic Resilience to Disasters: A Computable General Equilibrium Analysis of Water Service Disruptions." Journal of Regional Science 45(1), 75-112.

Van der Klis, Hanneke, Paul Baan, and Nathalie Asselman. 2005. "Historische Analyse van de Gevolgen van Overstromingen in Nederland. Een Globale Schatting van de Situatie rond 1950 
1975 en 2005." Rapport, Rijkswaterstaat RIZA.

Van der Meer, Ad, and Onno Boonstra. 2006. "Repertorium van Nederlandse Gemeenten 1812-2006." Dans data guide 2, DANS - Data Archiving and Networked Services.

Vigdor, Jacob. 2008. "The Economic Aftermath of Hurricane Katrina." The Journal of Economic Perspectives, 135-154.

Wolfers, Justin. 2006. "Did Unilateral Divorce Laws Raise Divorce Rates? A Reconciliation and New Results." American Economic Review 96 (5), 1802-1820.

Xiao, Yu. 2011. "Local Economic Impacts of Natural Disasters." Journal of Regional Science 51(4), $804-820$. 


\section{APPENDIX A: DATA}

This Appendix further elaborates on the quality of the data underlying our analysis. Figure A1 plots the mean of population growth in the different municipalities with the bars representing $95 \%$-confidence interval. What is readily seen is that there is a large difference in variance in the data between the years before around 1950 and the years thereafter. A closer inspection revealed that the standard deviations in population growth start decreasing from 1947, the year of the first census after the war. However, the year 1948 did see a huge increase in the variance in population growth. This was, however, caused by an outlier - the municipality of Leeuweradeel in Friesland - which, according to the data experienced a population decrease of almost $150 \%$. The source of error is either erroneous typing of data by the creators of the HDNG or problems with the original sources. ${ }^{2}$

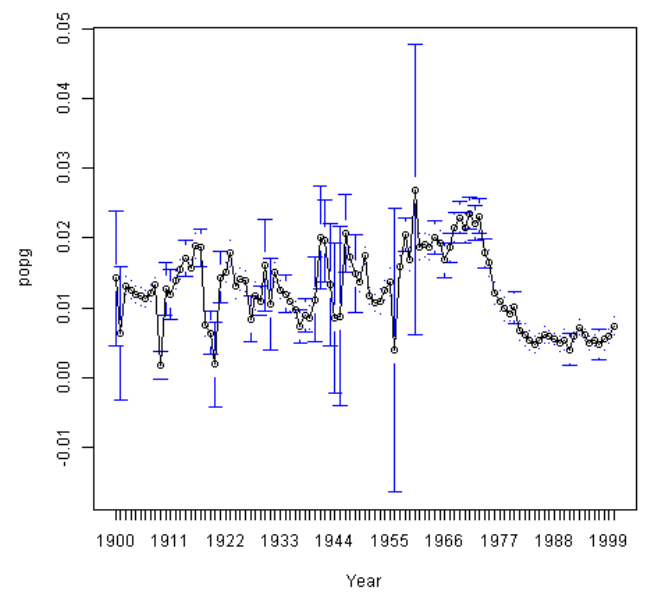

FIGURE A1: Mean of population growth over time with $95 \%$ confidence interval.

The solution here is simply to remove this particular observation, which yields Figure A2. Subsequently the standard deviations drop drastically from the year 1947 onwards. There are few universal rules of thumb for identifying outliers, and in this particular data set the definition of an outlier is likely to vary between the years. We know from other sources that there were large interregional variations in population growth rates, and an outlier could simply be a high growth municipality in a high growth region. Nevertheless, a plot showing outliers over time with a universal definition of outliers, can give some useful information about the data.

Figure A3 plots the number of outliers per year, where an outlier was defined as over ten times larger than the aggregate growth rate (in absolute values). Some peculiar patterns appear, which again raise questions about the reliability of the pre-1947 data. There were no censuses between 1930 and 1947, meaning that any data points between these years are results of extrapolations. The sharp increase in the number of outliers

\footnotetext{
${ }^{2}$ The HDNG appears to be riddled with errors in the years of WWII. Especially the year of 1944 is problematic: several municipalities are registered with a $150-200 \%$ population drop, just to experience an increase of a similar magnitude the following year. Again, sources behind the errors are something of an enigma. Inaccuracies in the coding may well be one source of error. But also lacking or erratic information about municipality changes as well as typos in the original data sets may have caused deviations.
} 


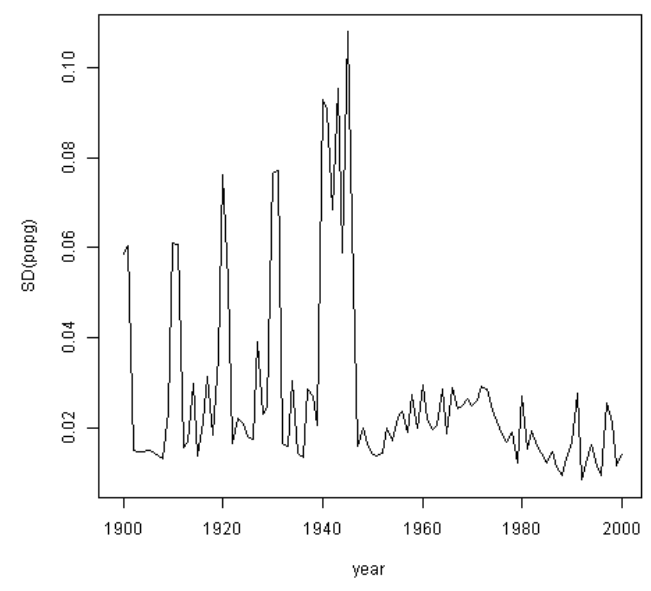

FIGURE A2: Mean of population growth over time with $95 \%$ confidence interval

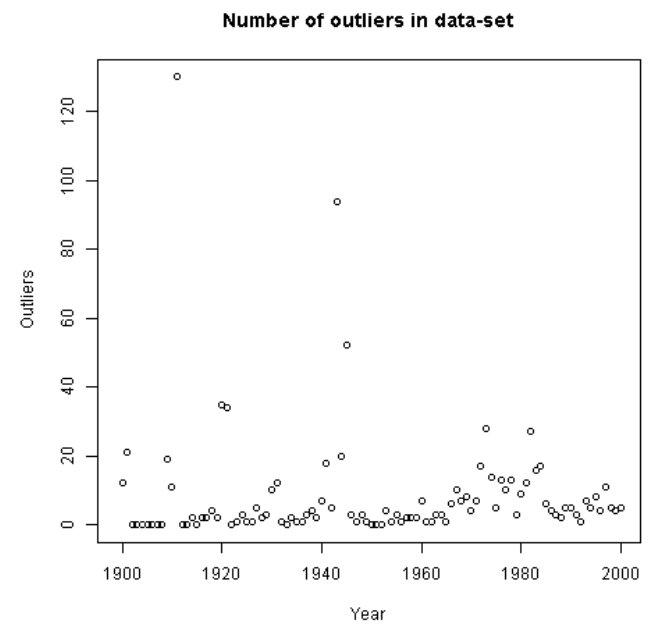

FIGURE A3: An outlier was here defined as population growth ten times higher than the aggregate growth rate.

in the years of the second World War (WWII) is therefore highly suspicious, as the data for these years should be based on the same extrapolations used for the data in the 1930s. We also see an increase in the number of outliers around 1980, but this may have a more natural explanation. The aggregate population growth was dropping fast towards the end of the 1970s, but with regional variations, possibly resulting in an increase in outliers. Another point is that all observations from the province of Flevoland are left out of the data set. This province was created with the closure of the Zuiderzee and subsequent land fill, and data series for the municipalities in the province are therefore incomplete. Figure A4 depicts the total population in the 
Netherlands from the original data set as well the total population in the data set with the reconstructed 2000-municipalities. The right bar shows the deviation between the two (in percentages). The line represents population (left axis), while the bars represent deviations (right axis). As is readily seen from the figure, deviations are systematically negative before the WWII while the error-margins become smaller and fluctuate between positive and negative. This means that before WWII the reconstructed data set systematically underestimate total population and produces larger errors.

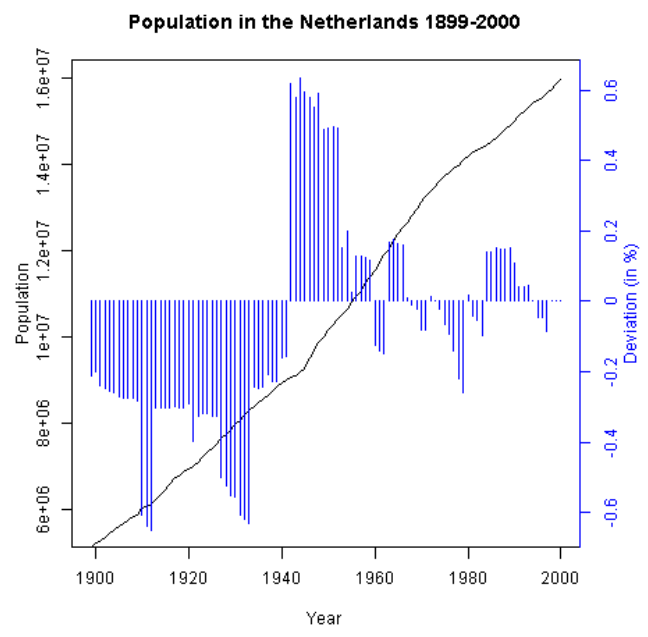

FIGURE A4: Population in the non-adjusted data set and deviation in the adjusted data set.

\section{APPENDIX B: MUNICIPALITIES IN THE TREATMENT GROUPS}

In this appendix we indicate the municipalities affected by the flood and the Deltaworks. Figure B1 shows the municalities which are coded as hit by the flood. Similarly, Figure B2 shows the municipalities which are coded as having been affected by the different phases of the Deltaworks construction. Although there is some spatial overlap, the correlation is not equal to one. 


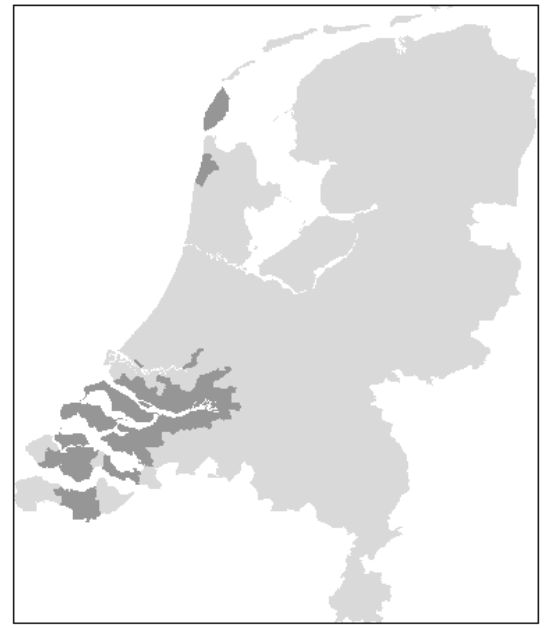

FIGURE B1: Municipalities hit by the flood. Treatment group is indicated with a darker colour. The number of municipalities amount to a total of 41 , where treatment switches on in 1953 for all of the affected municipalities.

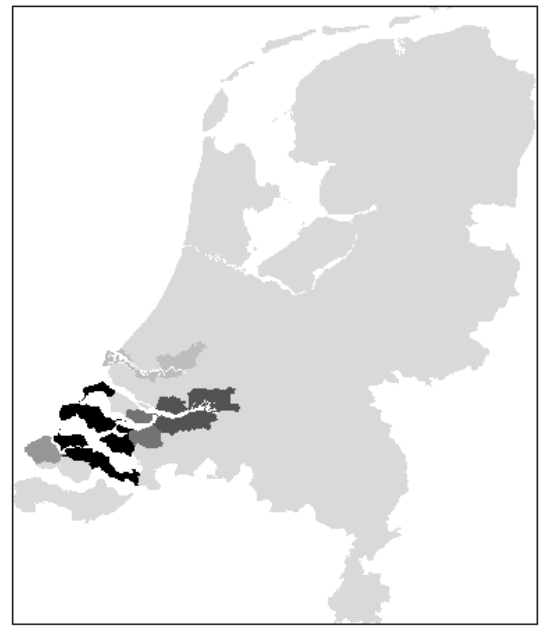

FIGURE B2: Municipalities affected by the Deltaworks. Later construction dates are indicated by progressively darker colours. The construction years (number of municipalities in parenthesis) are: 1958 (7), 1961 (4), 1965(3), 1969(7), 1971(2), 1986(6). 